further, as Dr. Babcock says, after once heating, the milk is sterilized and the process of drying and extracting may be completed at any subsequent time.

4th. The total solids may be determined on the ignited asbestos without the further trouble of previously drying to a constant weight.

Some recent experiments on the necessary amount of drying and extracting will be given in another paper.

\title{
THE UNITED STATES GALLON.
}

"The gallon is a vessel containing 583r2.2 grains (8.3389 pounds avoirdupois) of the standard pound of distilled water, at the temperature of maximum density of water, the vessel being weighed in air in which the barometer is 30 . inches at $62^{\circ} \mathrm{F}$." -(See report on "Weights and Measures," by Secretary of the Treasury, Senate Doc., 185\%.)

'This definition being somewhat obscure, occasion was taken' to write the 'Treasury Department, from which letter the following is quoted:

"Does this wording mean that the "gallon" is "rolume equal to that occupied by the above quantity of water under the conditions named; or does it intend a 'gallon' to be understood as meaning the quantity of liquid capable of being held by such standard vessel as above referred to, even after said vessel has been expanded by elevation of temperature? I take it that the latter view, although certainly stated, can hardly be intended."

The reply to this came from the office of the " "oast Survey," and read as follows:

"The standard gallon is a measure of capacity or volume. Its capacity was derived from standard weights, and in verifying and standardizing capacity measures it is the practice to determine the volumes by weighings. It is, therefore, to be understcod that the capacity of a gallon is measured by the weight of a volume of distilled water at maximum density, whose weight in air at $62^{\circ} \mathrm{F}$. Bar. 30. inches, equals 583r2.2 grains. 
"It follows, therefore, that a gallon is the measure of a constant volume, and that due allowance must be made for changes of temperature of a vessel used as a gallon measure."

A letter recently coming from the Treasury Department reads: "The value adopted by this office for the weight of 231 cubic inches of distilled water at its maximum density is $8.3389 \mathrm{lbs}$ : or $8.3316 \mathrm{lbs}$. at $15^{\circ} \mathrm{C}$. 'This reduced to $60^{\circ} \mathrm{F}$. gives a value of 8.3312 lbs."

Desiring to obtain a value in pounds for a U. S. Gallon of distilled water at $60^{\circ} \mathrm{F}$., said value to be carried beyond four decimal places, a very surprising degree of confusion was discovered among the authorities.

For instance :

U. S. Pharmacopoia, $18 \% 0 \ldots 583 \% 8.8862$ grains or 8.332698 lbs.

" " $1880 \ldots 58329.6$ " " 8.3328 "

Miller's Chemistry .........5831\%.3 " " 8.3310 " "

Am. Chemist, vol. 1, page 318.58319.8 " " " " " 8.3314

U.S. Treasury Depart

" " 8.3312 " "

“ Dispensatory (last ed.) _. 58328.886 " " " 68.332698 " “

Oldberg's "Weights and Meas-

nres," page 167_......58335.218 “ “ 8.333602571 “

From Barnard's "Metric System" we have:

1. cubic inch pure water at $62^{\circ} \mathrm{F}$, and under a pressure of 30. inches of mercury weighs in vacuo ........ 252.75965 grains.

Using Kopp's tables (Watt's Dict., vol. 3, p. 58, and interpolating by formula number one), we have:

$1 \mathrm{cu}$. in. water at $22^{\circ} \mathrm{F}$. becomes :

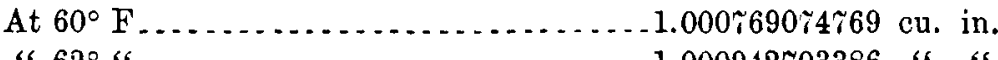

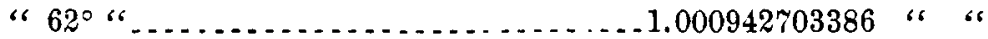

Hence :

$1 \mathrm{cu}$. in. at $62^{\circ} \mathrm{F}$. becomes $.9998265349101 \mathrm{cu}$. in. at $60^{\circ} \mathrm{F}$.

Hence :

$1 \mathrm{cll}$. in. of water at $60^{\circ} \mathrm{F}$, weighs in vacuo . . 252.8035026 grains. And 1. gallon (232 cu. in.) in vacuo .... $\left\{\begin{array}{c}58397.6091006 \text { grains or } \\ 8.3425155858 \text { lbs. }\end{array}\right.$ 
Referring again to Barnard's "Metric Nystem," we find : 1 cu. in. Water at $62^{\circ}$ in air at $62^{\circ}$ weighs . . 252.48843 grains.

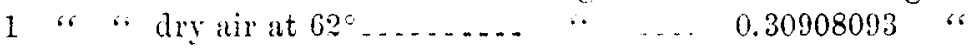

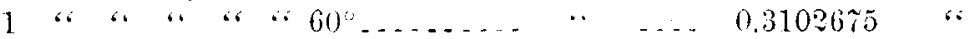

\section{Hence :}

1 cu. in. water at $62 \%$ in air at $60^{\circ}$..

Now $1 \mathrm{cu}$. in. of water at $62^{\circ}$ becomes, as we have seen:

$0.9998265349101 \mathrm{cu}$. in. at $60^{\circ}$; and the weight of this rolume of water at $60^{\circ}$ is equal to that of the entire cubic inch at $62^{\circ}$, plus the weight of a volume of air at $60^{\circ}$, equal to the difference between unity and said volume of water.

Hence: $.9998265349101 \mathrm{cu}$. in. water at $60^{\circ}$ and in air at $60^{\circ}$ weighs $25 \% 48 \% 29 \pi 24$ grains.

Ilence: $1 \mathrm{cu}$. in. water at $60^{\circ}$ weighed in air at $60^{\circ}$ and under 30 inches mercury weighs 252.5311035 r grains.

From these results we obtain for the weight of one L. S. Gallon (231 cu. in.) of pure water at $60^{\circ} \mathrm{F}$, and weighed in dry air at $60^{\circ}$ F. under a pressure of 30 inches of mercury : .58334 .6846936 i grains or $8.33352638481 \mathrm{lbs}$.

WIJLIAM P. MASON.

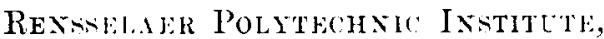
Tror. N. Y. 